\title{
ACUTE TOXICITY AND EFFECT OF FENITROTHION ON LIVER ESTERASE OF FISH
}

\author{
Solomon Sorsa
}

Department of Biology, Awassa College of Teacher Education

\begin{abstract}
The acute toxicity of fenitrothion (FNT) alone and combined with piperonyl butoxide (PBO) or triphenyl phosphate (TPP), and their effect on liver esterase (LE) activity of Gambusia holbrooki, Pseudorasobora parva and Oncorhynchus mykiss was studied in aquaria for 96h. The results indicated that fenitrothion is moderately toxic to the three species of fish tested, the toxicity being highest to O. mykiss followed by P. parva and G. holbrooki. Both FNT concentrations and the exposure time on the activity of LE and FNT (two way ANOVA P $<0.05$ ) caused more inhibition in G. holbrooki than P. parva. Pretreating fish with either PBO or TPP changed the acute toxicity level and LE sensitivity compared with those exposed to FNT alone. The acute toxicity level and susceptibility of LE to FNT was found to be inversely related. With additional studies P. parva and G. holbrooki have the potential to be used as bioindicator, and LE as biochemical biomarker of environmental pollution by FNT and other related compounds.
\end{abstract}

Key words/phrases: Fenitrothion, fish, liver esterase, synergists, toxicity

\begin{abstract}
Abbreviations: FNT (fenitrothion), PBO (piperonyl butoxide), TPP (triphenyl phosphate), LE (liver esterase), OP (organophosphate), ANOVA (analysis of variance), EEC (Economic Commission for Europe), WHO (World Health Organization), Glutathion (GSH), Glutathione S-transferase (GST), AchE (Acetylcholinesterase), MFO (Mixed Function Oxidase).
\end{abstract}

\section{INTRODUCTION}

Apart from the target pests, pesticides also affect the non-target organisms present in the ecosystem. Fish forms one of the important non-target organisms in the aquatic system, and is one of the major sources of protein for human being. It is necessary to examine the toxic effects of pesticides on fish, as they constitute an important link in the food chain and their contamination by pesticides disturb normal flow of energy in the aquatic ecosystem (Begum and Vijayaraghavana, 1995).

Begum and Vijayaraghavan (1996) stated that, pollution of aquatic environment by pesticides brings changes in the metabolic activities and alters physiological state thereby changing the biochemical constituent of aquatic organisms.

It is well known that xenobiotics are enzymatically metabolised in the liver of fish. According to Chambers et al. (1994), phosphrothionate insecticides and their active metabolites can be detoxified by a variety of hepatic mechanisms. This includes P-450-mediated dearylation, phosphorylation of aliesterases (carboxylesterases), catalytic hydrolysis of oxon by A-esterases, glutathion (GSH)-dependent detoxification, etc.

Enzymes have been recently used as biochemical biomarkers in order to assess and monitor the degree of pollution. According to Walker (1992), biomarkers, which can measure both exposure and toxic effect, are particularly valuable because they can provide a measurement of the harm that is caused by an environmental chemical.

The active ingredient in the formulated product sumithion, fenitrothion [0,0-dimethyl 0-(3-methyl4-nitrophenyl) phosphorothioate], is an organophosphate (OP) insecticide which is widely used in agriculture for crop protection, control of vector born diseases of public health and veterinary importance in various countries including China and Ethiopia (Self et al., 1973; Volpe and Mallet, 1981; Gandahusada et al., 1984; Ernst et al., 1991; 1994; Qifa et al., 1995). In Ethiopia, it is used to control armyworm (Spodptera exempta), African bollworm (Helicoverpa armigera), aphids, locusts, grasshoppers, plant bugs, etc. (Personal communication with Ministry of Agriculture). Piperonyl butoxide (PBO) and triphenyl phosphate (TPP) are also used as a synergist in pesticide formulations including fenitrothion (FNT).

Genlin et al. (1991) studied the effect of FNT in the aquatic ecosystem of paddy fields in China (in a 'rice-fish system'). According to them, when used at $375-750 \mathrm{~g}$ active ingredient (a.i.) ha ${ }^{-1}$ (50\% EC 500800 dilution), FNT is safe to fish. However, the effect of its sublethal concentrations on common species of fish has not been studied.

The objectives of the present study were therefore, to 1) determine the relative acute toxicity of FNT alone and combined with synergist to three 
fish species, namely, the Gambusia holbrooki, Psuedorasobora parva and Oncorhynchus mykiss; 2) examine the dose-response relationship of liver esterase (LE) activity in the G. holbrooki and P. parva, exposed to FNT; 3 ) assess the effect of synergists (PBO and TPP) as well as their respective combinations with FNT on the susceptibility of LE of G. holbrooki and P. parva; and 4) examine if there is any relationship between acute toxicity level and sensitivity of LE to FNT and its combinations with synergists.

\section{MATERIALS AND METHODS}

\section{Test chemicals and reagents}

Fenitrothion (FNT) of technical grade (93\% w/w) was obtained from Ningbo pesticide factory (China). Piperonyl butoxide (PBO) (90\%) and triphenyl phosphate (TPP) $(99+\%)$ were products of Aldrich chemical company inc. Alpha-naphthyl acetate was purchased from Shanghai first reagent factory; $\alpha$-naphthol from Xin-Tin chemical factory (Shanghai, P.R.China) was a product of roth; Fast blue B and Sodium laurylsulphate from Chemical and reagent supply station of Shanghai reagent factory (P.R.China). Bovine serum albumin was a product of Boehringer Company. All other chemicals were of analytical grade and obtained from local commercial sources.

\section{Fish species}

For acute toxicity test adults of two common species of freshwater fish namely, the Gambusia holbrooki (mosquito fish) (Girard, 1859) and Pseudorasobora parva (topmouth gudgeon) (Li and Fan 1996b) and one cold water fish, Oncorhynchus mykiss (rainbow trout) (Page and Burr, 1991) were used. The two fresh water fish were also used to study LE activity. These species were used because they are readily available and grow easily under laboratory conditions. G. holbrooki (0.2-0.26g) and P.parva $(0.6-1.0 \mathrm{~g})$ were procured from a local pet market and O. mykiss (2.5-4.3g) was obtained from fish hatcheries. All fish were acclimatized to the laboratory conditions for at least seven days prior to use. During the acclimatization period the water was changed daily and the fish were fed on commercially prepared fish food. The fish were judged to be in good physiological condition for use when no mortality was observed in the acclimatizing population. The fish selected for use in the study were starved at least for 24 hours before use and during the experiment period.

\section{Experimental conditions}

For both acute toxicity test and LE analysis, the experiment was carried out in 40 litter glass aquarium and the test diluents consisted of 20 litre aerated tap water. Twenty to thirty fish were grown in each aquarium (the mass/volume ratio

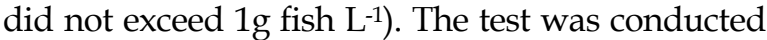
at water temperatures of $23 \pm 1^{0} \mathrm{C}$ for $\mathrm{G}$. holbrooki and P. parva, and $11^{\circ} \mathrm{C}$ for O. mykiss.

The stock solutions of test chemicals (FNT, PBO and TPP) were prepared by dissolving in acetone (99.5\% purity) and the known volume of each stock was added to 20 litres of diluents in the aquaria to attain the concentration.

The concentrations of FNT used for acute toxicity test were first determined based on tests conducted prior to the actual experiment. Concentrations of FNT used for le activity tests were determined based on the $96 \mathrm{~h} \mathrm{LC}_{50}$ for $\mathrm{G}$. holbrooki and P. parva (see the result section). The concentration of $\mathrm{PBO}$ (1mg L-1) was prepared based on recommendations of previous researchers (Glickman et al., 1977; Melanocon et al., 1977). The highest concentration of TPP $(0.2 \mathrm{mg} \mathrm{L}-1)$ that cause no mortality was considered for the experiment.

A 96h static exposure system was used in this study and fish were exposed to 1) different concentrations of FNT alone and, 2) $0.4 \mathrm{mg} \mathrm{L}-1$ of FNT after $24 \mathrm{~h}$ pre-treatment of either with PBO (1 mg L-1) or TPP (0.2mg L-1) and, 3) PBO or TPP alone. And the acute toxicity and LE activity in these exposed groups was compared with that of the control. In all cases fish that were not exposed to chemicals served as the control group. In addition, to test the effect of acetone on acute toxicity and LE activity, fish were exposed to acetone $(15 \mu \mathrm{l} \mathrm{L}-1)$ alone under similar conditions to the experimental group.

\section{Acute toxicity test}

The susceptibility of the fish to FNT was determined according to the method of Macek and McAllister (1970). The end point of bioassay was death of the fish and death was defined as complete immobilization and failure to respond to gentle prodding. As mortality occurred the dead fish were immediately removed from the test aquarium and the median lethal concentration (LC50) was determined based on the method of Finney (1964). This method involves conversion of the concentrations tested and the corresponding observed mortality to $\log$ and probit values, respectively. The values were then used for further statistical analysis. 


\section{Liver homogenate preparation and esterase analysis}

From each treatment group, six fish were used to estimate esterase activity. Liver homogenate was prepared following the method of Van Asperen (1962). Alpha-naphthylacetate was used as a substrate and the stock solution was prepared by dissolving in acetone. The diazoblue-sodium laurylsulphate solution (consisted of two parts of a $1 \%$ fast blue B and five parts of a $5 \%$ solution of sodium laurylsulphate) was used as an indicator to estimate the naphthol produced in the reaction system. The difference in colour absorbency between the control and the different treatments was measured with double-beam spectrophotometer (Shimazu, Japan) at a wavelength of 600 $\mathrm{nm}$ using a $1 \mathrm{~cm}$ light path cell. The amount of $\alpha$ naphthol produced in the reaction was estimated from the standard curve and the LE activity calculated and expressed as nmol of $\alpha$-naphthol produced $\mathrm{min}^{-1} \mathrm{mg}$ protein ${ }^{-1}$. Total protein was determined by the method of Lowry et al. (1951). Each assay was run in triplicate and the results are presented as the mean \pm SD of esterase activity.

\section{Statistical analysis}

A two-way analysis of variance (ANOVA) was used to determine treatment effect and Duncan's test was used to determine differences between the means. The significance level was set at 0.95 and is expressed as a p-value 0.05 .

\section{RESULTS AND DISCUSSIONS}

\section{Acute toxicity}

Table 1 shows the $\mathrm{LC}_{50}$ of FNT, and FNT combined with PBO or TPP for three species of fish. Of the three species tested, the LC 50 of FNT was lowest for O. mykiss and highest for G. holbrooki. According to the criteria of Economic Commission for Europe (ECE) pesticides with $\mathrm{LC}_{50} \leq 1 \mathrm{mg} \mathrm{L}^{-1}$ are categorized as very toxic and those with $1 \mathrm{mg} \mathrm{L}^{-1}>\mathrm{LC}_{50} \leq 10 \mathrm{mg}$ $\mathrm{L}^{-1}$ are considered moderately toxic to aquatic organisms (Klein et al., 1992). Considering this classification, FNT was moderately toxic to all the three species of fish tested. However, relative toxicity of FNT is approximately two-fold more toxic to P. parva and O. mykiss than G. holbrooki.

Compared with the fish species tested in this study, the $96 \mathrm{~h} \mathrm{LC}_{50}$ of a teleost fish, Anguilla anguilla, $\left(0.2 \mathrm{mg} \mathrm{L}^{-1}\right)$ was very low indicating that FNT is extremely toxic to this species (Ferrando et al., 1991). Shao-Nan and De-Fang (1996) studied the acute toxicity of malathion to these three species of fish in our laboratory and found the $96 \mathrm{~h}$ $\mathrm{LC}_{50}$ to be $0.7,14.5$ and $0.25 \mathrm{mg} \mathrm{L}^{-1}$ for G. holbrooki, $P$. parva and O. mykiss, respectively. The data show that FNT is approximately five-fold less toxic than malathion to G. holbrooki and O. mykiss, but ninefold more toxic to $P$. parva. The results (Table 1) clearly indicate the presence of species related difference in susceptibility of fish to FNT.

In all three species tested, the $\mathrm{LC}_{50}$ of FNT for fish pre-treated with $\mathrm{PBO}$ had decreased compared with that of FNT alone. Pretreating the fish with $\mathrm{PBO}$ increased the toxicity of FNT two-fold, 1.4-fold and 1.2-fold for O. mykiss, P. parva and G. holbrooki, respectively. The present result seems to be consistent with that of Reinbold and Metcalf (1976). These authors found that PBO increased the toxicity of methoxychlor, trifluralin and aldrin to Lepomis cyanellus (greenish). They postulated that the increased toxicity was due to the insecticides not being metabolised (detoxified). Shao-Nan and De-Fang (1996) also reported increased malathion toxicity to P.parva in the presence of $\mathrm{PBO}$.

Table 1. Acute toxicity of fenitrothion alone and combined with PBO or TPP to three fish species, $G$. holbrooki P.parva and O. mykissi. ( $\mathrm{n}=30$ for G. holbrooki and P. parva; $\mathrm{n}=20$ for O. mykissi).

\begin{tabular}{cccc}
\hline $\begin{array}{c}\text { Pesticide or } \\
\text { synergist } \\
\text { mixture }\end{array}$ & \multicolumn{3}{c}{$\mathrm{LC}_{50}\left(\mathrm{mg} \mathrm{L}^{-1}\right)$} \\
\cline { 2 - 4 } & G. holbrooki & P. parva & O. mykissi \\
\hline \multirow{2}{*}{ FNT } & $3.71^{\mathrm{a}}$ & $1.64^{\mathrm{c}}$ & $1.31^{\mathrm{d}}$ \\
& $(3.49-3.93)$ & $(1.48-1.80)$ & $(0.77-1.85)$ \\
FNT + PBO & $2.99^{\mathrm{b}}$ & $1.20^{\mathrm{d}}$ & $0.66^{\mathrm{e}}$ \\
& $(2.60-3.38)$ & $(0.33-1.94)$ & $(0.55-0.77)$ \\
FNT + TPP & $1.25^{\mathrm{d}}$ & $0.73^{\mathrm{e}}$ & $0.84^{\mathrm{e}}$ \\
& $(0.81-1.69)$ & $(0.57-0.89)$ & $(0.76-0.92)$ \\
\hline
\end{tabular}

Note: FNT, fenitrothion; PBO, pepironyl butoxide; TPP, triphenyl phosphate; Values in parenthesis are 95\% confidence intervals; Values with similar letter are not significantly different $(\mathrm{P}>0.05)$.

Compared with that of FNT alone, the $\mathrm{LC}_{50}$ of FNT to all three species of fish pre-treated with TPP had decreased (Table 1). Triphenyl phosphate (TPP) increased the toxicity of FNT three-fold to G. holbrooki and approximately two-fold to P. parva and O. mykiss. No similar data were found to compare the present results with the previous studies conducted elsewhere. Although the concentration of TPP is greater $\left(1 \mathrm{mg} \mathrm{L}^{-1}\right)$ and the pesticide used is different, Shao-Nan and De-Fang (1996) found higher toxicity of malathion to G. holbrooki, P. parva and O. mykiss pre-treated with TPP. TPP is a known inhibitor of carboxyl esterase (Oppenoorth and Welling, 1976). Carboxyl esterase belongs to a group of hydrolytic enzymes, collectively called non-specific esterases, that are important in detoxification of OP compounds and 
synthetic pyrethroids (Dauterman, 1976; Kao et al., 1985; Chambers et al., 1994). Hence, the observed increase in acute toxicity of FNT to TPP pre-treated fish may be due to inability of the fish to detoxify FNT.

\section{Liver esterase activity}

Acetone used to dissolve test chemicals had no effect on LE activity and the values were not different from the control. Liver esterase activity of both G. holbrooki and P. parva, was found to be very high. In particular, G. holbrooki exhibited the highest activity (583.3 nmol min.-1 $\mathrm{mg}$ protein), which is approximately 1.3 -fold higher than that of P. parva (451.7 $\mathrm{nmol} \mathrm{min.}{ }^{-1} \mathrm{mg}$ protein $\left.{ }^{-1}\right)$. This result shows differences in the inherent specific activity of LE between the two species. Li and Fan (1996a) also reported a similar result for the two species.

The pattern of LE activity in G. holbrooki and $P$. parva exposed to different concentrations of FNT is shown in Figures $1 \mathrm{~A}$ and $\mathrm{B}$, respectively. A two way ANOVA demonstrated a significant $(\mathrm{P}<0.05)$ difference in both FNT concentrations and the exposure time of the activity of le in the two species of fish. When exposed to 0.4 and $1.3 \mathrm{mg} \mathrm{L}^{-1}$ of FNT for 24h, the maximum activity and the minimum activity observed in G. holbrooki were 56 and $49.0 \%$ of the control, respectively. A similar concentration-dependent pattern was observed at the end of 48 and 96h. Similarly, in P. parva, LE activity progressively decreased with the increase in concentrations (except for $0.2 \mathrm{mg} \mathrm{L}^{-1}$ ). However, the rate of decline was not similar for the two species, i.e., somewhat less for P. parva than for $G$. holbrooki (Fig. 1).

Results of this study demonstrated that LE activity was inhibited, at all concentrations used, in both species of fish investigated. This shows the presence of esterase, sensitive to FNT, in the liver of G. holbrooki and P. parva. Using electrophoresis, Li and Fan (1996b) identified one isoenzyme from $G$. holbrooki and two from P. parva LE and found one of the isoenzymes in P. parva to be similar to that of $G$. holbrooki. They also studied the effect of malaoxon on the LE and reported the existence of malaoxonsensitive LE in P. parva but not in G. holbrooki.

Data concerning the mechanism of fish LEs on pesticides are not available. However, there are related studies that are conducted on the mechanism of LEs in mammals. For example, Lauwerys and Morphy (1969) studied paraoxon binding by rat liver and plasma and concluded that phosphorylation of esterases was probably the primary means of reducing the paraoxon concentration in these preparations. Other studies similarly concluded that AliE (eserin insensitive Besterases) are an important alternate phosphorylation site for OPs and reduce the concentration inhibition of acetylcholinesterase (AchE) (Funnum and Sterri, 1981; Maxwell et al., 1988). Chambers et al. (1990) investigated detoxification of the oxons of six phosphorothionate insecticides (methyl parathion, parathion, chlorpyrifos-methyl, chlorpyrifos, EPN and leptophos) in rats and arrived at a similar conclusion. In addition, they stated that the presence of AliE in the liver, in close proximity to where much oxon would be generated by mixed function oxidase (MFO) (cytochrome P-450) mediated desulfuration reaction, would allow them the opportunity to be readily phosphorylate and prevent much of the hepatically generated oxon from entering the circulation. Furthermore, they concluded that AliE phosphorylation is strongly implicated as a mechanism of noncatalytic detoxification of OPs, which can afford the animal significant protection from intoxication.
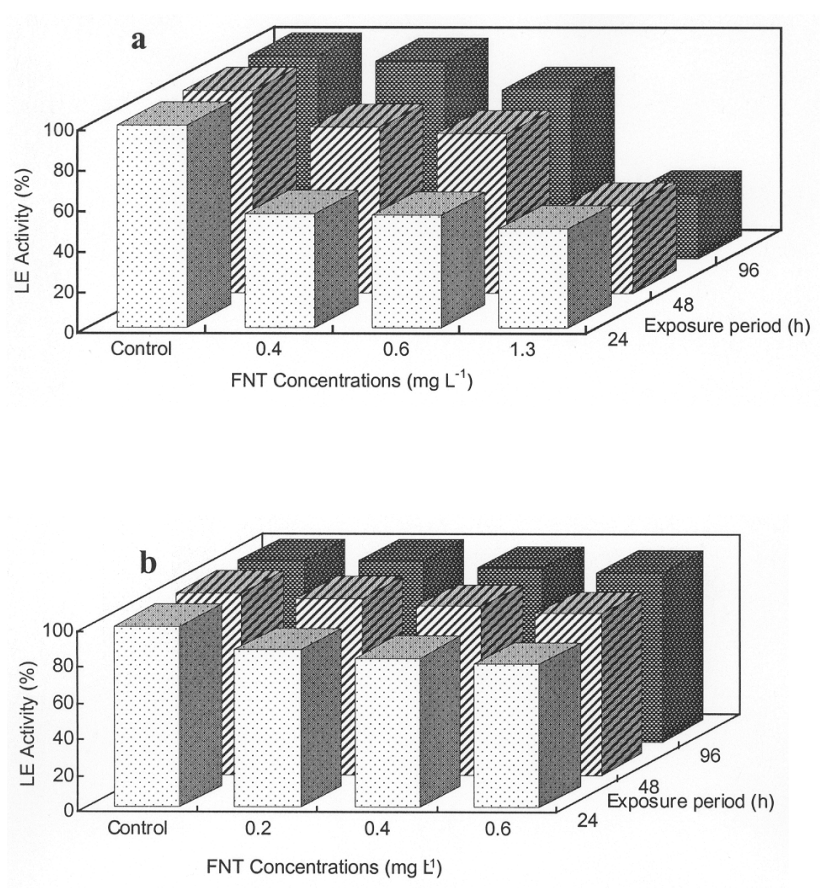

Fig. 1. Effect of fenitrothion on liver esterase activity of A) G. holbrooki B) P. parava. (Note that LE activity is expressed as percentage of the control).

Earlier results described above suggest that inhibition of LE results from binding to oxons of OP pesticides, which as a result become phosphorylated and decreases the concentration of esterase in the liver. Therefore, inhibition of LE activity 
observed in G. holbrooki and P. parva in this study may be due to the binding of fenitroxon to esterase. This shows that the livers of G. holbrooki and $P$. parva are capable of sequestering or noncatalytically detoxifying FNT.

As shown in Figs 1a and b the activity of LE of both species is strongly inhibited within the first 24h exposure period and progressively decreased inhibition with time. This decreased inhibition (increased activity or recovery) with time may be due to decrease in the concentration of FNT and its active metabolite (fenitroxon) in the test system and/or in the fish with time. The exceptionally lowered LE activity with time observed in G. holbrooki exposed to highest concentration $(1.3 \mathrm{mg}$ $\left.\mathrm{L}^{-1}\right)$ may be due to concentration-dependent permanent inactivation of the enzyme.

Comparison of the response in the two species exposed to similar concentrations $(0.4$ and $0.6 \mathrm{mg}$ $\mathrm{L}^{-1}$ ) revealed that FNT caused more inhibition of LE in G. holbrooki than P. parva. This difference in susceptibility between the two species is expected to cause difference in the rate of detoxification and consequently contribute to difference in the acute toxicity of FNT (Fig. 1).

To investigate the effect of $\mathrm{PBO}$ on the susceptibility of LE, fish were pre-treated with $1 \mathrm{mg}$ $\mathrm{L}^{-1}$ of $\mathrm{PBO}$ for $24 \mathrm{~h}$ before adding FNT to the test system. The result indicated that in G. holbrooki exposed to $\mathrm{PBO}$ alone, LE activity was higher than the controls. However, in P. parva, it produced a 6.6, 2.4 and $1.1 \%$ decline at 24,48 and $96 \mathrm{~h}$ exposure periods, respectively (Table 2).

The LE activity in fish exposed to FNT alone $(0.4$ $\mathrm{mg} \mathrm{\textrm {L } ^ { - 1 }}$ ) and pre-treated with $\mathrm{PBO}$ was also compared. In both species pre-treating with $\mathrm{PBO}$ caused more activity than those exposed to FNT alone (Table 2). This may be explained by considering inhibition of MFO by $\mathrm{PBO}$ and the subsequent reduction of fenitroxon production. Inhibition of MFO might have significantly reduced production of fenitroxon and this decreased phosphorylation of LE, thus increasing activity in these than in those exposed to FNT alone. Therefore, this suggests that detoxification action of LE is reduced by PBO treatment.

In both species investigated, liver esterase was strongly inhibited by TPP alone $\left(0.2 \mathrm{mg} \mathrm{L}^{-1}\right)$. As shown in Table 2, LE activity of G. holbrooki is more sensitive to TPP inhibition than that of P. parva. This agrees well with the result reported by $\mathrm{Li}$ and Fan (1996b). These authors studied susceptibility of LE isoenzymes to TPP inhibition and found that both G. holbrooki and P. parva LEs contain TPP sensitive isoenzymes. Their report also indicated that LE of G. holbrooki is more sensitive to TPP inhibition than that of P. parva.

The influence of TPP on the sensitivity of LE to FNT was studied and the result compared (Table 2). In both species the activity was significantly decreased $(\mathrm{P}<0.05)$ in those pre-treated with TPP. Furthermore, the previous study (Solomon Sorsa et al., 1999) also demonstrated that, in G. holbrooki exposed to FNT concentrations ranging from 0.4 to $1.3 \mathrm{mg} \mathrm{L}^{-1}$ and pre-treated with TPP after exposure to $0.4 \mathrm{mg} \mathrm{L}^{-1}$ of FNT, AchE activity was significantly depressed. This shows that TPP had increased the susceptibility of fish LE to FNT. This finding is supported by three facts 1) LEs of both species was inhibited by FNT alone, 2) both species of fish contain TPP sensitive LEs (23), and 3) TPP is a known specific inhibitor of carboxyl esterase (Maxwell et al.,1988) which is one of the LEs.

\section{Relationship Between Acute Toxicity and Liver Esterase Activity}

FNT is more toxic to $P$. parva ( $\mathrm{LC}_{50} 1.64 \mathrm{mg} \mathrm{L}^{-1}$ ) than G. holbrooki (LC50 $3.71 \mathrm{mg} \mathrm{L}^{-1}$ ) (Table 1). This toxicity difference observed between the two species may be caused by several factors combined together. According to Chambers et al. (1990), the acute toxicity of any poison is governed by its inherent potency at the target site and the effective concentration reaching that target. Moreover, factors such as the ability of noncatalytic detoxification, AchE sensitivity, rate of phosphorothionate activation, and the rate of catalytic detoxification can determine the phosphorothionate's acute toxicity level.

The intrinsic LE activity of G. holbrooki is higher (approximately 1.3-fold) than that of $P$. parva and this shows that LEs of G. holbrooki are more susceptible to FNT inhibition than that of $P$. parva. Chambers et al. (1990) stated that, inhibition of LEs is mainly due to phosphorylation of aliesterases by OP compounds. Moreover, liver aliesterases occupy an alternative phosphorylation site for OPs and are capable of appreciably reducing the concentration of OPs required to inhibit the AchE. They also suggested that low inhibition of aliesterases by phosphrothionates is because of low sensitivity, thus the pesticide could more easily escape the hepatic aliesterases and cause inhibition. Thus, it can be suggested that detoxification of FNT by LES in G. holbrooki was higher than that of P.parva. This suggestion agrees with the higher acute toxicity of FNT to P. parva than G. holbrooki. 


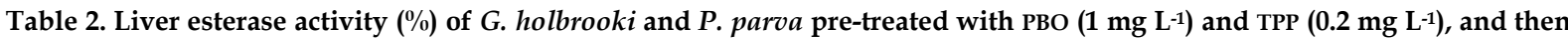
exposed to fenitrothion $\left(0.4 \mathrm{mg} \mathrm{L}^{-1}\right)$.

\begin{tabular}{ccccccc}
\hline Treatments & \multicolumn{2}{c}{$24 \mathrm{~h}^{\mathrm{a}}$} & \multicolumn{2}{c}{ 48h $^{\mathrm{a}}$} & \multicolumn{2}{c}{ 96h $^{\mathrm{a}}$} \\
\cline { 2 - 7 } & G. holbrooki & P. parva & G. holbrooki & P. parva & G. holbrooki & P.parva \\
\hline Control & 100 & 100 & 100 & 100 & 100 & 100 \\
FNT & 56.2 & 82.3 & 81.9 & 92.7 & 97.5 & 96.3 \\
PBO & 101.2 & 93.4 & 109.5 & 97.6 & 119.3 & 98.9 \\
FNT + PBO & 78.9 & 90.7 & 84.7 & 92.3 & 110.2 & 98.1 \\
TPP & 45.7 & 59.3 & 46.2 & 68.6 & 52.9 & 82.2 \\
FNT + TPP & 51.8 & 54.7 & 58.7 & 57.1 & 67.4 & 61.1 \\
\hline
\end{tabular}

a Exposure time. For PBO and TPP treatments, exposure period does not include pre-treatment time, i.e., $24 \mathrm{~h}$.

Note: $\mathrm{FNT}=$ fenitrothion, $\mathrm{PBO}=$ Piperonyl butoxide, $\mathrm{TPP}=$ triphenyl phosphate

Furthermore, results of a study conducted by Solomon (1999) revealed that hepatic glutathione S-transferase (GST) activity of G. holbrooki is 1.3-fold higher than that of $P$. parva. In addition, GST of $P$. parva was found to be more sensitive to inhibition by FNT than G. holbrooki. The presence of higher amount of inherent GST activity and lower sensitivity to FNT observed in G. holbrooki is indicative of higher detoxification capability of this species. Therefore, it seems likely that GSTdependent detoxification of FNT might have also contributed to low acute toxicity to G. holbrooki.

\section{CONCLUSION}

The study revealed that fenitrothion is moderately toxic to the three species of fish tested, the toxicity being highest to $O$. mykiss ( $\mathrm{LC}_{50} 1.31 \mathrm{mg} \mathrm{L}^{-1}$ ) followed by $P$. parva ( $\mathrm{LC}_{50} 1.64 \mathrm{mg} \mathrm{L}^{-1}$ ) and $G$. holbrooki (3.71 $\left.\mathrm{LC}_{50} \mathrm{mg} \mathrm{L}^{-1}\right)$. Pre-treatment with two common synergists, PBO $\left(1 \mathrm{mg} \mathrm{L}^{-1}\right)$ and TPP $(0.2 \mathrm{mg}$ $\left.\mathrm{L}^{-1}\right)$, significantly increased the toxicity of FNT to $O$. mykiss, P. parva and G. holbrooki.

Liver esterases of both G. holbrooki and P. parva were inhibited by FNT, the G. holbrooki LEs being highly sensitive to inhibition than $P$. parva. However, in PBO and TPP pre-treated group, it was $P$. parva that become susceptible to FNT at the end of the exposure period. These findings could be indicative of the participation of LES in detoxification of FNT.

The inhibitory effect of LE activity caused by FNT increased with concentration. Although the level of effect could be different under field condition, the present study revealed that field application rates that leave FNT concentrations of $0.4 \mathrm{mg} \mathrm{L}^{-1}$ and more in aquatic environment could be dangerous for the survival of common fish, such as G. holbrooki and P. parva and related species.
With further characterization, therefore, LE seems to be a candidate biochemical biomarker of environmental pollution by FNT and other related compounds. Furthermore, with additional comparative studies, $P$. parva and G. holbrooki may be used as bioindicator for monitoring and assessment of environmental chemicals.

\section{REFERENCES}

1. Begum, G. and Vijayaraghavan, S. (1995). In vivo toxicity of demethioate on proteins and transaminases in the liver tissue of fresh water fish Clarias batrachus (Linn). Bull. Environ. Contam. Toxicol. 54:370-375.

2. Begum, G. and Vijayaraghavan, S. (1996). Alterations in protein metabolism of muscle tissue in the fish Calrias batrachus (Linn) by commercial grade dimethoate. Bull. Environ. Contam. Toxicol. 57:223-228.

3. Chambers, H., Brown, B. and Chambers, J.E. (1990). Noncatalytic detoxication of six organophosphorous compounds by rat liver homogenates. Pestic. Biochem. Physiol. 36:8-315.

4. Chambers, J.E., Ma, T., Brone, J.S. and Chambers, H.W. (1994). Role of detoxication pathways in acute toxicity levels of phosphorothionate insecticides in the rat. Life Sci. 54:1357-1364.

5. Dauterman, W.C. (1976). Exteramicrosomal metabolism of insecticides. In: Pesticide Biochemistry and Physiology, pp. 149-176 (Wilkinson C.F., ed.) Plenum Press, New York.

6. Ernst, W., Julien, G. and Hennigar, P. (1991). Contamination of ponds by fenitr-othion during forest spraying. Bull. Environ. Contam. Toxicol. 46:815-821.

7. Ernst, W., Wade, S., Hennigar, P. and Julien, G. (1994). Toxicity to aquatic organisms of pond water contaminated by fenitrothion during forest spraying. Bull. Environ. Contam. Toxicol. 52:612618. 
8. Ferrando, M.D., Sancho, E. and Andreu, E. (1991). Comparative acute toxicity of selected pesticides to Anguilla anguilla. J. Environ. Sci. Health 26:491-498.

9. Finney, D.J. (1964). Statistical Methods in Biological Assay, Charles Griffin and Company Lt. London, 329 pp.

10. Funnum, F. and Sterri, S.H. (1981). Factors modifying the toxicity of organopho-sphorous compounds including sarin and soman. Fundam. Appl. Toxicol. 1:143.

11. Gandahusada, S., Flaming, G.A., Sukamto, S., Damar, T., Sumarto, S., Sustriayu, N., Bang, Y.H., Arwati, S. and Arif, H. (1984). Malaria control with residual fenitrothion in Central Java, Indonesia. Bull. WHO. 62:783 -794.

12. Genlin, L., Zhang Z., Gang, G. and Jin, G. (1991). Influence of fenitrothion on aquatic ecosystem of rice- fish. Southwest China J. Agric. Sci. 4:51-57. (in Chinese, abstract in English).

13. Girard, C.F. (1859). Ichthyological notices. Proc. Acad. Nat. Sci. Phila. V. 11:56-68, 100-104, 113-122.

14. Glickman, A.H., Statham, C.N. Wu, A. and Lech, J.J. (1977). Studies on the uptake, metabolism, and disposition of pentachlorophenol and pentachloroanisol in rainbow trout. Toxicol. Appl. Pharmacol. 41:649-658.

15. Kao, L.R., Motoyama, N. and Dauterman, W.C. (1985). Multiple forms of esterase in mouse, rat and rabbit liver, and their role in hydrolysis of organophosphorus and pyrethriod insecticides. Pestic. Biochem. Physiol. 23:66-73.

16. Klein, A.W., Apel, P. and Goedicke, J. (1992). UBAprinciple on criteria and procedure for environmental assessment of pesticides. . Chemosphere. 24:793-815.

17. Lauwerys, R.R. and Murphy, S.D. (1969). Interaction between paraoxon and tri-o-tolylphosphate in rat. Toxicol. Appl. Pharmacol. 14:348.

18. Li, S. and Fan, D. (1996a). Correlation between biochemical parameters and susceptibility of freshwater fish to malathion. J. Toxicol. Environ. Health. 48:413-157.

19. Li, S. and Fan, D. (1996b). Activity of esterases from different tissues of freshwater fish and responses of their isoenzymes to inhibitions. J. Toxicol. Environ. Health. 51:149-157.

20. Lowry, O.H., Rosebrough, N.J., Farr, A.C. and Randall, R.J. (1951). Protein measurment with folinphenol reagent. J. Biochem. 193:265-275.

21. Macek, K.J. and McAllister, W.A. (1970). Insecticide susceptibility of some common fish family representatives. Trans. Am. Fish. Soc. 99:20-27.

22. Maxwell, W.M., Brecht, K.M., Lenz, D.E. and O'Neill, B.L. (1988). Effects of carbo-xylesteras inhibition on carbamate protection against soman toxicity. J. Pharmacol. Exp. Ther. 246:986.

23. Melanocon, M.J., Saybolt, J. and Lech, J.J. (1977). Effect of piperonyl butoxide on disposition of di- 2-ethylhexyl phathalate by rainbow trout. Xenobiotica. 7:633-640.

24. Oppenoorth, F.J., and Welling, W. (1976). Biochemistry and physiology of resistance. In: Insecticide Biochemistry and Physiology, pp. 507-551 (Wilkinson, C.F., ed.). Plenum Press, New York.

25. Qifa, H., Peijun, Z. and Zhenhua, T. (1995). The mechanism of resistance to fenitrothion in the rice stem borer Chilo suppresslis Walker. Acta Entomologia Sinica. 38:266-271. (in Chinese, abstract in English).

26. Page, L.M. and Burr, B.M. (1991). A Field Guide to Freshwater Fishes. North America, North of mexico. The Peterson Field Guide Series. Boston, pp. $1-432$.

27. Reinbold, K.A. and Metcalf, R.L. (1976). Effect of the synergist piperonyl butoxide on metabolism of pesticides in green sunfish. Pesti.Biochem. Physiol. 6:401-412.

28. Self, L.S., Ree, H.I., Lofgren, C.S., Shim, J.C., Chow, C.Y., Shin, H.K. and Kim, K.H. (1973). Aerial application of ultra-low-volume insecticide to control the vector of Japanese encephalitis in Korea. Bull. WHO. 49:353-357.

29. Shao-Nan, L. and De-Fang, F. (1996). Correlation between biochemical parameters and susceptibility of freshwater fish to malathion. J. Toxicol. Environ. Health. 48:413-418.

30. Solomon Sorsa (1999). Comparative Toxicity and Sublethal Effects of Fenitrothion on Some Biochemical Parameters of Selected fish Species. Ph.D. Thesis. Zhejiang University, P.R. China, p. 110.

31. Solomon Sorsa, Shao-Nan, L. and Defang, F. (1999). Brain acetylcholenesterase response and recovery in mosquitofish (Gambusia holbrooki) exposed to fenitrothion. Chines J. Pestic. Sci. 1:6172.

32. Van Asperen, K. (1962). A study of housefly esterase by means of a sensitive colorimeteric method. J. Ins. Physiol. 8:401-414.

33. Volpe, G. and Mallet, V.N. (1981). High performance liquid chromatography of fenitr-othion and seven derivatives- a study of their recovery from water using XAD resins as compared with organic solvent. Chromatographia. 14:333-336.

34. Walker, C.H. (1992). Biochemical responses as indicators to toxic effects of chemicals in ecosystem. Toxicol. Lett. 64/65:527-533. 